Lovell, R. (2016) Links between natural environments and mental health: evidence briefing (EIN018). Natural England. Available at http:// publications.naturalengland.org.uk/publication/5748047200387072?c ategory=6159558569361408 (last accessed September 2017)

Marselle, M., Irvine, K. \& Warber, S. (2014) Examining group walks in nature and multiple aspects of well-being: a large-scale study. Ecopsychology, 6, 134-147.

Mitchell, R. J., Richardson, E. A., Shortt, N. K., et al (2015) Neighborhood environments and socioeconomic inequalities in mental well-being. American Journal of Preventive Medicine, 49, 80-88.

Thompson Coon, J., Boddy, K., Stein, K., et al (2011) Does participating in physical activity in outdoor natural environments have a greater effect on physical and mental wellbeing than physical activity indoors? A systematic review. Environmenta Science and Technology, 45, 1761-1772. van den Berg, A. \& Clusters, M. (2011) Gardening promotes neuroendocrine and affective restoration from stress. Journal of Health Psychology, 16, 3-11.

van den Berg, A. \& van den Berg, C. (2011) A comparison of children with ADHD in a natural and built setting. Child: Care, Health and Development, 37, 430-439.

van den Berg, A., Koole, S. \& van der Wulp, N. (2003) Environmental preference and restoration: (how) are they related? Journal of Environmental Psychology, 23, 135-146.

Vardakoulias, O. (2013) The Economic Benefits of Ecominds: A Case Study Approach. NEF Consulting. Available at https://www.mind.org. uk/media/338566/The-Economic-Benefits-of-Ecominds-report.pdf (last accessed September 2017).

\section{THEMATIC} PAPER

\title{
Feel blue, touch green: examples of green spaces promoting mental health
}

\author{
Claire Henderson-Wilson ${ }^{1}$ and Rona Weerasuriya ${ }^{2}$
}

School of Health and Social Development, Deakin University, Burwood, Australia, email claire. Burson-wilson@deakin.edu.au ${ }^{2}$ School of Health and Social Development, Deakin University, Burwood, Australia
The design of hospital environments with an increased focus on incorporating nature and natural features has been reported to have multiple health and well-being benefits. This paper reports on three Australian case studies that each investigated the relationship between green spaces and people's mental health. The results suggest that gardens or other green spaces should be included within plans for future healthcare design. While we acknowledge that there are a range of considerations in the allocation of healthcare resources and programmes for maximum benefit, we believe that those programmes which highlight the beneficial outcomes for people with mental illness of 'feeling blue and touching green' are worth implementing.

There is strong historical evidence, dating back to the early civilisations in China, Greece and Persia, to support the idea that contact with nature, through viewing or being in landscapes with vegetation, water and other natural features, relieves stress and provides human health benefits (Velarde et al, 2007). In Europe, the earliest hospitals were typically located in monasteries, which had cloistered gardens and provided a peaceful and calming environment for patients (Velarde $e t$ al, 2007)

The design of hospital environments with an increased focus on incorporating nature and natural features has been reported to have multiple health and well-being benefits for users. For example, research indicates that patients have increased levels of social functioning, self-mastery and sense of coherence, and a significant reduction in symptoms of anxiety and depression as a result of participating in both active and passive therapeutic activities carried out in gardens (Corazon et al, 2010). Additionally, research has shown that living close to green spaces significantly mediates individual resilience and life coping skills (van den Berg et al, 2010). Other international evidence demonstrates a strong connection between time spent in green spaces and people's enhanced mental health and well-being (Townsend $e t$ al, 2015).

This paper reports on three small-scale Australian studies that each investigated the relationship between green spaces and people's mental health. All studies received university ethics approval and were conducted in accordance with ethical research guidelines. Given the qualitative design of the studies, they had small sample sizes, so the findings cannot be generalised to the wider population.

\section{Case study 1. Perceptions of contact with nature in relation to mental health}

The study, commissioned by the South Australian Department of Environment, Water and Natural Resources, explored people's perceptions of 'nature' and how it affects their well-being and the use of state-managed parks as a vehicle for facilitating this relationship.

Face-to-face semi-structured interviews were undertaken with 14 park users and 14 non-users of parks. Opportunistic sampling was used to recruit participants in two different parks/open space areas within the Adelaide area for the parkuser interviews. A similar approach was used to recruit participants in a shopping centre close to the selected park areas for the non-user interviews. Interviews were recorded and transcribed prior to data analysis. Both thematic and 'rich point 
analysis' were used to identify the range and diversity of views and experiences.

The participants reported a range of mental health benefits related to spending time in parks. Those raised by the majority of participants included: experiencing positive emotional responses, perceived effect on people's health and well-being, spiritual well-being, opportunities for social contact and opportunities for alone time. A large group of participants made comments about mental health aspects such as stress alleviation, relaxation, elevated mood, lowered anxiety and reflection.

The following statements highlight the theme 'experiencing positive emotional responses':

It's almost like a meditation for me to able to come to the park every day ... it just helps me to be calm and to get my mental health under control.

I am a psychologist so I happen to think that mental health is important and my own experience and my professional belief is that contact with nature and just that removing yourself from some of the stresses of everyday life is a very beneficial thing.

I'd say more important for me is ... mental health. You're relaxing and you can think things through while you're here. It's a good place to do that. There's not going to be any interruptions.

\section{Case study 2. Effects of participation in outdoor programmes for people with mental illness}

The study surveyed participants from an organisation located in Melbourne that provides services based on outdoor adventure education and recreation for people with a psychiatric disability. Participants were surveyed at two time points to determine if there were any health and well-being effects of participation in outdoor programmes over time. Participants with a range of mental health issues were recruited to the study only if they were deemed to have the ability to understand and follow the survey instructions.

The survey collected data on the effectiveness of outdoor programmes from participants through end-of-activity surveys and the Health Education Impact Questionnaire (heiQ) survey on health literacy (Osborne et al, 2007). The heiQ is a user-friendly, relevant and psychometrically sound instrument. It is designed to be applied across a broad range of chronic conditions to evaluate programme participation (Osborne et $a l, 2011)$. Four specific subscales of the heiQ were used, measuring: positive and active engagement in life; self-monitoring and insight; constructive attitudes and approaches; and social integration and support.

Data were analysed using the STATA data analysis and statistical software package and were either descriptive in nature (means, standard deviations, frequencies) or involved $t$-tests (independent samples or paired) to determine whether there were any statistically significant changes in the heiQ constructs over time.
One hundred and sixty-two participants were recruited. Mean scores on the four subscales of the heiQ increased slightly across the two time points, indicating that participation in outdoor programmes may have positive effects on participants' ability to self-manage their mental illness, to engage in life and to feel socially connected. However, caution is required when interpreting the results as there were no statistically significant findings. This is largely due to the limited numbers of participants surveyed at both time points ( $n=41$, due to drop-outs as a result of participants' fluctuating mental health) but the findings suggest that with larger sample sizes more of a difference across time as a result of participating in outdoor programmes might be observed.

In addition to surveying participants, a subsample of 17 older adults were recruited for a focus group, where the researchers further explored perceptions of the benefits of participating in outdoor programmes. The findings demonstrated that spending time outdoors resulted in a range of mental health benefits. For example, many participants mentioned experiencing relaxation, stress relief and rejuvenation as a result of attending outdoor programmes.

Additionally, some participants mentioned how spending time in nature alleviated their symptoms of depression, as indicated by the following statements:

Especially when you suffer from depression, it's nice, helps you a lot, rests your mind.

Being in nature is so relaxing!

\section{Case study 3. Exploring users' mental health experiences in hospital gardens}

This study was set in a hospital in an outer suburb of Melbourne. Seventy-two users of the hospital gardens were interviewed to record their experiences. The sample comprised staff $(n=36)$, patients $(n=18)$ and visitors $(n=18)$. The phenomenological study reflected the hermeneutic process of enquiry. The data collected were thematically coded and the findings were compared and contrasted to contextualise the evidence.

A majority of the findings from the phenomenological study reflected global evidence outlining psychological, emotional, social and spiritual benefits from accessing hospital gardens. Findings indicated that the hospital gardens provided patients, staff and visitors with a range of mental health and well-being benefits. The following statements highlight this theme:

It's a space that you can come to where ... I guess you feel a little bit removed from the hospital-type environment. You can be ... have a mix of emotions, you know ... but often they can be depressing, you know ... or often they can make you ... sad or whatever ... whereas these gardens are a space where it's separate and it's visual.

I think everyone who comes here feels that partly through the garden, you know, partly through the opportunity that the people who live here have to work in the garden and the consideration that the garden can have therapeutically and emotionally on their sense of well-being. 
Anyone who comes into this environment feels that they are in a place of calm, peace, healing and relaxation, which is a contrast to how our modern society works, which is busy, crazy, fast and noisy.

The findings of this study have important consequences for the evidence-based design of healthcare settings aimed at supporting and empowering users to maintain and enhance their health and well-being. Apart from the benefits to users' mental health and well-being, the symbolic value of holistic versus medical focus, progressive ideals and value placed on clients and employees have strong suggestive power. This, in turn, has resultant economic implications for healthcare providers.

\section{Conclusions}

It appears that time spent in green spaces can provide people with a range of opportunities to enhance their mental health. It can increase people's capacity to self-manage their mental illness and acknowledge the realities of their limitations, and their ability to develop the confidence to seek support from interpersonal relationships as well as from community-based organisations (Osborne et al, 2007). Additionally, the Australian case studies reported here, albeit of limited sample size, highlight the importance of incorporating gardens into healthcare settings and contribute to the green healthcare evidence base accessible to designers, planners, policy makers and hospital administrators who aim to create and support health-promoting settings.
Although the findings cannot be generalised to the wider population, as a whole they suggest that gardens or other green spaces should be included within healthcare plans. In conclusion, while we acknowledge that there are a range of considerations in the allocation of healthcare resources and programmes for maximum benefit, we believe that those programmes which highlight the beneficial outcomes for people with mental illness of 'feeling blue and touching green' are worth implementing.

\section{References}

Corazon, S. S., Stigsdotter, U. K, Nielson, A. G., et al (2010) Developing the nature-based therapy concept for people with stress related illness at the Danish healing forest garden Nacadia. Journal of Therapeutic Horticulture, 20, 35-50.

Osborne, R. H., Elsworth, G. R. \& Whitfield, K. (2007) The Health Education Impact Questionnaire (heiQ): an outcomes and evaluation measure for patient education and self-management interventions for people with chronic conditions. Patient Education Counselling, 66, 192-201.

Osborne, R. H., Batterham, R. \& Livingston, J. (2011) The evaluation of chronic disease self-management support across settings: the international experience of the Health Education Impact Questionnaire Quality Monitoring System. Nursing Clinics of North America, 46, 255-270.

Townsend, M., Henderson-Wilson, C., Warner, E., et al (2015) Healthy Parks, Healthy People: The State of the Evidence 2015. Report prepared for Parks Victoria, School of Health and Social Development, Deakin University, Melbourne. Available at http:// www.hphpcentral.com/article/global-research-compilation-provesstrong-link-between-nature-and-human-health (last accessed September 2017).

van den Berg, A. E., Maas, J., Verheij, R. A., et al (2010) Green space as a buffer between stressful life events and health. Social Science and Medicine, 70, 1203-1210.

Velarde, M. D., Fry, G. \& Tveit, M. (2007) Health effects of viewing landscapes - landscape types in environmental psychology. Urban Forestry and Urban Greening, 6, 99-212.

\section{THEMATIC} PAPER

\title{
Horticultural therapy in a psychiatric in-patient setting
}

\author{
Miguel de Seixas, ${ }^{1}$ David Williamson, ${ }^{2}$ Gemma Barker $^{3}$ and Ruth Vickerstaff 4
}

\begin{tabular}{l}
${ }^{1}$ Consultant Psychiatrist, \\
Cambridgeshire and \\
Peterborough NHS Foundation \\
Trust, UK, email miguel. \\
deseixas@cpft.nhs.uk \\
${ }^{2}$ Specialist Occupational \\
Therapist, Cambridgeshire and \\
Peterborough NHS Foundation \\
Trust, UK \\
\hline${ }^{3}$ Specialist Occupational \\
Therapist, Cambridgeshire and \\
Peterborough NHS Foundation \\
Trust, UK \\
\hline${ }^{4}$ Advanced Occupational \\
Therapist, Cambridgeshire and \\
Peterborough NHS Foundation \\
Trust, UK
\end{tabular}

In-patient mental health services have a duty to constantly seek to improve patient experience and to assist in the development of new skills that can aid recovery. Horticultural therapy can be implemented in an economic, social and environmentally sustainable way to achieve those goals.

In the UK, the National Institute for Health and Care Excellence (NICE) is a public body of the Department of Health that provides national guidance and advice on matters relating to health and social care. NICE publishes guidance, advice, quality standards and information services for health, public health and social care. Quality standards are documents that set out the priority areas for quality improvement. In 2011 and 2012 NICE published quality standards on service user experience in adult mental health services (NICE, 2011) and on patient experience in adult care in the National Health Service (NHS) (NICE, 2012). Among other points, these documents stress the importance of access to meaningful activities for people in hospital for mental healthcare that should include creative and leisure activities, exercise, self-care and community access where appropriate, facilitated by trained health or social care professionals (NICE, 2011), as well as of effective interactions with staff (NICE, 2012). 